Article

\title{
Graphene Oxide as a Nanocarrier for a Theranostics Delivery System of Protocatechuic Acid and Gadolinium/Gold Nanoparticles
}

\author{
Muhammad Sani Usman ${ }^{1, *}$, Mohd Zobir Hussein ${ }^{1, *(1)}$, Aminu Umar Kura ${ }^{2}$, Sharida Fakurazi ${ }^{3}$, \\ Mas Jaffri Masarudin ${ }^{4}$ (D) and Fathinul Fikri Ahmad Saad ${ }^{5}$ \\ 1 Materials Synthesis and Characterization Laboratory, Institute of Advanced Technology (ITMA), \\ Universiti Putra Malaysia, Serdang 43400, Selangor, Malaysia \\ 2 Pharmacology, Faculty of Basic Health Sciences, Bauchi State University, Bauchi 65, Nigeria; \\ ameenkura@gmail.com \\ 3 Department of Human Anatomy, Faculty of Medicine and Health Sciences, Universiti Putra Malaysia, \\ Serdang 43400, Selangor, Malaysia; sharida.fakurazi@gmail.com \\ 4 Department of Cell \& Molecular Biology, Faculty of Biotechnology and Biomolecular Sciences, \\ Universiti Putra Malaysia, Serdang 43400, Selangor, Malaysia; masjaffri@upm.edu.my \\ 5 Centre for Diagnostic and Nuclear Imaging, Faculty of Medicine and Health Sciences, \\ Universiti Putra Malaysia, Serdang 43400, Selangor, Malaysia; ahmadsaadff@gmail.com \\ * Correspondence: muhusma@gmail.com (M.S.U.); mzobir@upm.edu.my (M.Z.H.); \\ Tel.: +601-0309-3348 (M.S.U.); +603-8946-8092 (M.Z.H.)
}

Received: 4 January 2018; Accepted: 19 January 2018; Published: 24 February 2018

\begin{abstract}
We have synthesized a graphene oxide (GO)-based theranostic nanodelivery system (GOTS) for magnetic resonance imaging (MRI) using naturally occurring protocatechuic acid (PA) as an anticancer agent and gadolinium (III) nitrate hexahydrate (Gd) as the starting material for a contrast agent,. Gold nanoparticles (AuNPs) were subsequently used as second diagnostic agent. The GO nanosheets were first prepared from graphite via the improved Hummer's protocol. The conjugation of the GO and the PA was done via hydrogen bonding and $\pi-\pi$ stacking interactions, followed by surface adsorption of the AuNPs through electrostatic interactions. GAGPA is the name given to the nanocomposite obtained from Gd and PA conjugation. However, after coating with AuNPs, the name was modified to GAGPAu. The physicochemical properties of the GAGPA and GAGPAu nanohybrids were studied using various characterization techniques. The results from the analyses confirmed the formation of the GOTS. The powder X-ray diffraction (PXRD) results showed the diffractive patterns for pure GO nanolayers, which changed after subsequent conjugation of the Gd and PA. The AuNPs patterns were also recorded after surface adsorption. Cytotoxicity and magnetic resonance imaging (MRI) contrast tests were also carried out on the developed GOTS. The GAGPAu was significantly cytotoxic to the human liver hepatocellular carcinoma cell line (HepG2) but nontoxic to the standard fibroblast cell line (3T3). The GAGPAu also appeared to possess higher T1 contrast compared to the pure Gd and water reference. The GOTS has good prospects of serving as future theranostic platform for cancer chemotherapy and diagnosis.
\end{abstract}

Keywords: GO nanosheets; gadolinium; protocatechuic acid; gold nanoparticles; diagnostics; anticancer; theranostics

\section{Introduction}

The discovery of graphene and graphene derivatives in the field of nanoscience and nanotechnology has attracted a great deal of research attention, this is because of their wide range of exceptional properties, including electrical, mechanical and thermal properties, to mention a few [1]. 
Although the extent of these properties vary from one graphene derivative to another, the basic properties of the carbon-based materials can be found in all graphene derivatives, this has made the application of the materials to become diverse. Graphene was discovered in 2004 by Geim and his team, which has earned them a Nobel Prize in Physics [2]. The derivatives of graphene are graphene oxide (GO) and reduced graphene oxide (rGO), which are classified based on the type of chemical alteration done on the structure of graphene material. Graphene and the derivatives are equally classified based on their number of layers (single layer, bi-layer and multilayer), which make them differ in their surface chemistry and dimensions [3].

For biomedical applications of the graphene derivatives, such as drug delivery and biosensing, $\mathrm{GO}$ is often the favorite amongst the others due to its carboxylic acid structure [4]. Just like graphene, GO is a two-dimensional layered nanomaterial with a high surface area to volume ratio. It differs from graphene mainly by its uncharged epoxide $(\mathrm{O})$ and hydroxyl $(\mathrm{OH})$ groups, which are located in the basal plane of the graphene-like nanosheets [4]. This enables them to have hydrogen bonding and other interactions at the layer surface. Other interactions, such as $\pi-\pi$ and non-convalent bonding are also likely in the GO plane due to the presence of free unboned $\pi$ electrons $[5,6]$. Unlike hydrophobic graphene, GO is hydrophilic and hence, more soluble and stable in colloids than its graphene counterpart [4]. In addition, GO has the ability to control drug release and it can be easily functionalized with other molecules. The aforementioned properties make GO a preferable nanocarrier in biomedicine, especially in drug and gene delivery systems.

Lately, GO has been used in bioimaging and theranostic applications. Theranostic systems involves the simultaneously delivery of therapeutic and diagnostic agents to the desired targets. Theranostic systems can be bimodal or multimodal, depending on the set-up of the delivery system. In bimodal mode, a therapeutic agent is loaded together with two diagnostic agents or a diagnostic agent with two imaging modalities on a nanocarrier, for drug delivery and imaging applications [7]. Theranostic delivery systems (TDS) are particularly of great interest in anticancer research. This is because cancer chemotherapy, which is the most utilized form of cancer treatment, involves diagnosis with sophisticated molecular imaging techniques, such as magnetic resonance imaging (MRI) and computed tomography (CT) [5]. Most of the imaging techniques require contrast agents due to the poor visibility in subject tissues; the contrast agents are mostly administered prior to the tests [8]. The TDS reduces the toxicities of these diagnostic agents as well as that of the toxic therapeutic agents by targeting the cancer cells [9]. In addition, TDS offers the possibility of monitoring the release of the cancer agents at the target site/cancer cells location [7]. MRI was used for the diagnostic aspect test in this work, while gadolinium and AuNPs were used as contrast agents for the MRI.

Gadolinium is a trivalent rare earth metal that has been used in improving the contrast of MRI machines since 1984 [10], the contrast agents are used to increase the intensity of the signals generated in the MRI (T1 and T2). T1 is the spin-lattice relaxation signal and T2 is the spin-spin relaxation signal. Gold nanoparticles (AuNPs) are known for their superior surface properties, such as very high surface area to volume ratio and surface plasmon resonance (SPR) [11]. These properties among others make them useful in imaging applications.

A handful of articles have reported GO-based nanoparticles for theranostic applications. The GO nanosheets were in most of the reports conjugated or functionalized with either polymers or ligands to improve their biocompatibilities [12,13]. In our work, no conjugating substance was employed for biocompatibility or adsorption of the guest molecules on the GO nanolayers. The GO nanosheets were prepared and directly loaded with firstly the MRI contrast agent (gadolinium $(\mathrm{Gd})$ ) by electrostatic interaction, which was trailed by doping of the anticancer agent (protocatechuic acid) through $\mathrm{OH}$ bonding and $\pi-\pi$ stacking interactions.

Protocatechuic acid (PA) is a natural compound found in medicinal plants, such as Hibiscus sabdariffa L. and Ginkgo biloba L. The compound is known for its several medicinal properties, including anti-hypertensive [14] anti-antibacterial [15], anti-inflammatory and analgesic [16], and anti-aging effects [17]. It has also been reported to have anticancer [14] properties. This influenced our choice of 
the drug as the anticancer drug in this work and as a replacement for the established toxic anticancer agents, such as doxorubicin (DOX) [12,13], which has been reported in various articles. In this work, GO nanosheets were used to conjugate the natural compound (PA) simultaneously with the Gd contrast agent (GAGPA). Subsequently, the GAGPA nanohyrid was used to adsorb AuNPs as the second MRI contrast agent (GAGPAu). GAGPAu is also referred to graphene oxide (GO)-based theranostic nanodelivery system (GOTS). Although most articles use AuNPs for CT contrast improvement, it was used as supporting MRI contrast in this work.

\section{Results and Discussion}

This section highlights the results from the characterization of the pure phases and developed nanocomposites. Studies have shown that aromatic molecules mostly chemotherapeutics can be doped on the surface of $\mathrm{GO}$ nanosheets using their $\mathrm{sp}^{2}$-carbon sites as base for $\pi-\pi$ stacking interactions or the $\mathrm{COOH}$ groups for hydrogen bonding with the guest molecules. The aforementioned interactions have been confirmed and meticulously discussed according to the methods of characterization. The GOTS is developed based on the concept of theranostic delivery system (TDS) with therapeutic and diagnostic agents both loaded on the GO layers. Figure 1a illustrates the theranostic arrangement of the GO nanosheets conjugated with protocatechuic acid and gadolinium, with AuNPs adsorbed on the surface in a typical TDS setting.

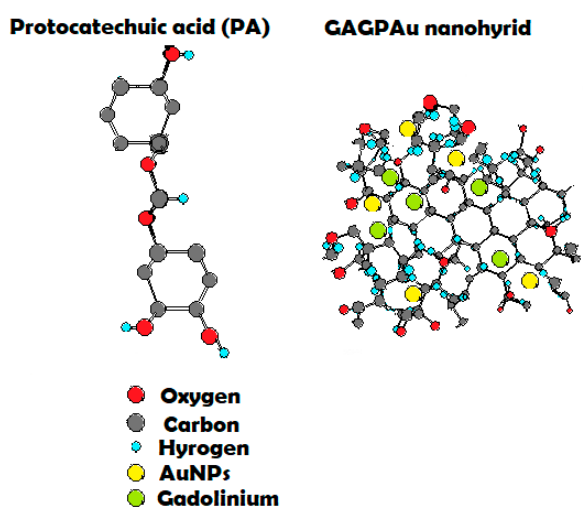

(a)

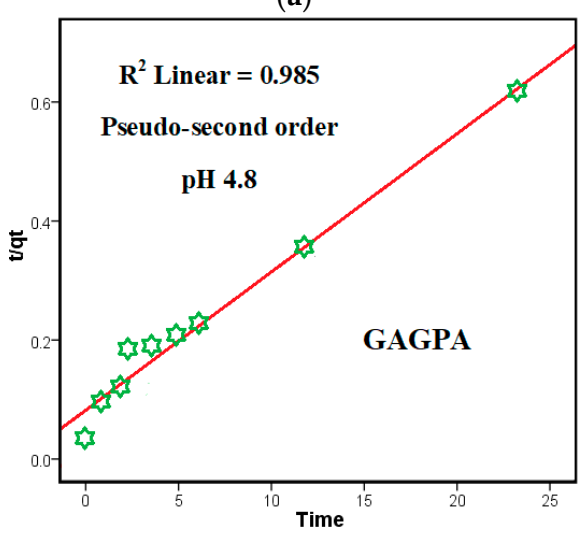

(c)

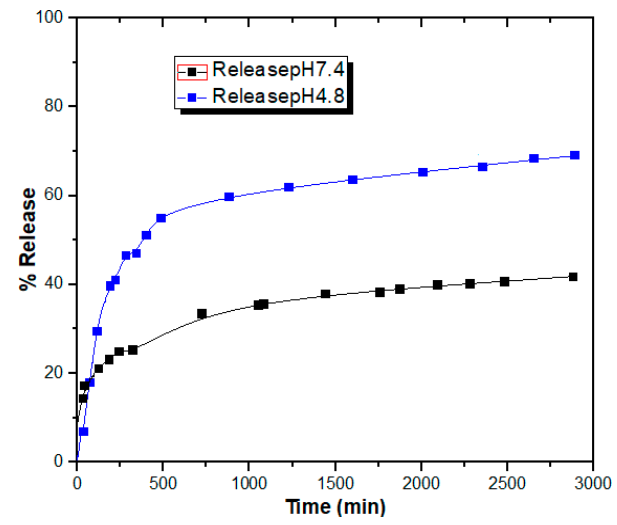

(b)

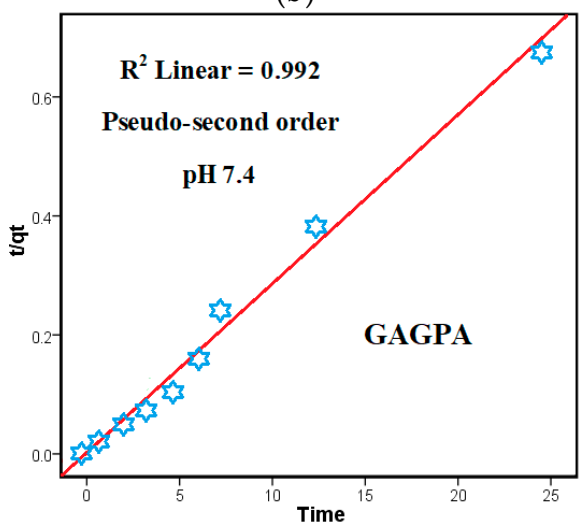

(d)

Figure 1. (a) Active agents-loaded of GAGPAu nanocomposite in a theranostic nanodelivery system. Diagnostic agents, gadolinium (green) and AuNPs (yellow) and the anticancer agent, PA are attached on a graphene sheet via hydrogen bond, $\pi-\pi$ interaction and electrostatic interaction (GOTS); (b) Release profiles of protocatechuic acid from GO-Gd/PA nanocomposite (GAGPA) in pH 7.4 and 4.8 media; (c) Pseudo-seconder order kinetic plot of protocatechuic acid release data at $\mathrm{pH} 4.8$ medium from GAGPA nanocomposite (Drug-GO/Gd); (d) Pseudo-seconder order kinetic plot of protocatechuic acid release data at pH 7.4 medium from GAGPA nanocomposite (Drug-GO/Gd). 


\subsection{Protocatechuic Acid Release Pattern from GAGPA Nanocomposite}

Profiles of the drug release from GAGPA nanocomposite were obtained both in PBS media ( $\mathrm{pH} 7.4$ and 4.8). As shown in Figure 1b, the drug release started at around $5 \mathrm{~min}$ and stopped after about $3000 \mathrm{~min}$, with over $65 \%$ of the drug was released in $\mathrm{pH} 4.8$ and $40 \%$ in $\mathrm{pH} 7.4$. This is understandably due to the gradual dissolution and detachment of the anticancer agent from the GO nanocarrier, which are bind by hydrogen-bonding and $\pi-\pi$ stacking to the hydroxyl groups as well as the $\mathrm{sp}^{2}$ carbon atoms of the GO nanosheets [12,17]. Although based on the aromatic structure of the drug, the hydrogen bonding between the carboxylic and epoxide groups of GO and the hydroxyl groups of the protocatechuic [18] is favored in this case. The higher release process in the acidic medium than in the alkaline medium could also be due to the increase in hydrogen bonding propensity under acidic conditions, which would result in higher competition among the hydrogen bearing groups. This process weakens the hydrogen bonding between the carboxylic groups and the hydroxyl groups of the GO nanolayers and the protocatechuic acid respectively [5], hence the variation in the release profiles. The release in the alkaline medium could also be influenced by ion-exchange reaction [19]. The simulation release mechanism implies higher release in the actual cancer cells than in blood stream or non-cancer cells, since the host environment of cancer cells is acidic and vice versa for the blood and tissues. This has been established since 1960 by Ehrlich, where tumor-targeting is said to be based on the acidity of the pathological sites [20]. The release profiles are indicating the successful adsorption of the anticancer agent on GO nanosheets, which is in conformity with the anticancer evaluation of the nanocomposite as discussed in the cytotoxicity studies of this work. It is worthy of mentioning, that the percentage drug release profiles of our GAGPA nanocomposite is much higher than the reported drug release profiles of GO-conjugated/DOX nanocomposite [21].

Protocatechuic Acid Release Kinetics from GAGPA Nanocomposite

The kinetic release of protocatechuic acid from the GAGPA nanocomposite was studied for clear understanding of the drug release behavior. Three kinetic models were used to study the drug release:

$$
\begin{array}{cc}
\text { Pseudo-first order : } & \ln \left(q_{e}-q_{t}\right)=\ln q_{t}-k t \\
\text { Pseudo-second order : } & \frac{t}{q_{t}}=\frac{1}{k q_{e}^{2}}+\frac{t}{q} \\
\text { Parabolic diffusion : } & \left(1-M_{t} / M_{o}\right) / t=k t^{-0.5}+b
\end{array}
$$

In the above equations, $q_{e}$ and $q_{t}$ represent the amounts of PA released at equilibrium $(e)$ and at time $(t)$, while $M_{t}$ and $M_{o}$ are representing the amount of the PA in the nanocarrier at the time of release $t$ and 0 , respectively and $k$ is the rate constant [22]. Although the drug release data was analyzed with the 3 models, only the best fit plot was presented in this paper (Figure 1c,d). However, the correlation coefficients $\left(\mathrm{R}^{2}\right)$ deduced from all the three model plots are presented in Table 1 . The pseudo-second order kinetic model was observed to be the best fit for the PA release data from the GAGPA nanohyrid, with correlation coefficients $\left(\mathrm{R}^{2}\right)$ of 0.985 for $\mathrm{pH} 7.4$ and 0.992 for $\mathrm{pH} 4.8$. As reported in Table 1 , the $\mathrm{R}^{2}$ of the first order is 0.863 ( $\mathrm{pH} 7.4$ ) and 0.563 ( $\mathrm{pH} \mathrm{4.8),} \mathrm{while} \mathrm{the} \mathrm{parabolic} \mathrm{diffusion} \mathrm{is} 0.936(\mathrm{pH} 7.4)$ and 0.932 ( $\mathrm{pH} 4.8$ ). Further, the rate constant (k) derived from the pseudo-second order model is $4.9 \times 10^{-3}$ and $2.3 \times 10^{-3} \mathrm{~g} / \mathrm{mg}$ h for $\mathrm{pH} 7.4$ and 4.8 , respectively. Other information deduced from the model and its plot is the percentage saturation $(\%)$ and $t_{1 / 2}(\mathrm{~min})$, which have all been summarized in Table 1. 
Table 1. Correlation coefficients $\left(\mathrm{R}^{2}\right)$, percentage saturation (\%), rate constants $(\mathrm{k})$, and half-life $\left(t_{1 / 2}\right)$ of protocatechuic acid release at $\mathrm{pH}$ 7.4 and 4.8 PBS from GAGPA as derived from the models.

\begin{tabular}{ccccccc}
\hline \multirow{2}{*}{$\begin{array}{c}\text { Sample } \\
\mathbf{p H}\end{array}$} & \multicolumn{3}{c}{ Correlation Coefficients $\mathbf{( R}^{\mathbf{2}}$ ) } & $\begin{array}{c}\text { Percentage } \\
\text { Saturation (\%) }\end{array}$ & $\begin{array}{c}\text { Rate } \\
\text { Constant (k) }\end{array}$ & $\boldsymbol{t}_{\mathbf{1 / 2}}(\mathbf{m i n})$ \\
\cline { 2 - 4 } & Pseudo-First Order & Pseudo-Second Order & Parabolic Diffusion & & & \\
\hline 7.4 & 0.863 & 0.992 & 0.936 & 50 & $4.9 \times 10^{-3}$ & 90 \\
4.8 & 0.563 & 0.985 & 0.932 & 80 & $2.3 \times 10^{-3}$ & 170 \\
\hline
\end{tabular}

\subsection{Powder X-ray Diffraction Studies}

The step by step loading of the guest molecules into the GO nanocarrier was monitored by PXRD, in which the X-ray patterns were obtained at various stages. The patterns of the pure GO synthesized from the graphite material using improved Hummer's method were obtained. Subsequently, the diffractograms of the pure drug was also taken and lastly the diffractograms of GO after Gd and protocatechuic acid loading (GAGPA) as well as after coating with AuNPs GO-Gd/PA-Au, as named GAGPAu in Figure 2a. The pure GO nanosheets XRD reflection can be seen at around $2 \theta$ position = $10^{\circ}$ degrees $(\mathrm{d}=8.5 \AA)$ in the GO diffractogram [23,24], indicating successful preparation of the GO nanolayers. However, emphasis is on the GAGPA nanocomposite which was obtained after drug and Gd loading. The GAGPA diffractogram appears to have shifted a bit towards the lower $2 \theta$ angle on the plane, and broader in shape than the pure GO diffractogram. This is an indication of hydrogen-bonding and $\pi-\pi$ stacking bonding between the carboxylic groups of GO [25] and hydroxyl groups of the drug as suggested by the drug release profiles $[5,26,27]$. It also could be due to electrostatic interaction between Gd and GO surface. The interactions appear to be at the surface only and not within the GO interlayer sheets. Generally, the PA and Gd loadings did not result in significant changes in phase in the GO nanosheet structure. Nevertheless, after coating with AuNPs (GAGPAu), the diffractogram assumes the diffractogram of the pure AuNPs. Only a weak reflection of the GAGPA can be noticed in the diffractogram. All other reflections are distinctive of the face centered cubic structure (FCC) of AuNPs $\left(111,200,220\right.$, at $38^{\circ}, 45^{\circ}$ and $65^{\circ}$ theta positions, respectively) [11]. This is due to the electrostatic interaction between the negatively charged GO surface and the positively charged AuNPs [12].

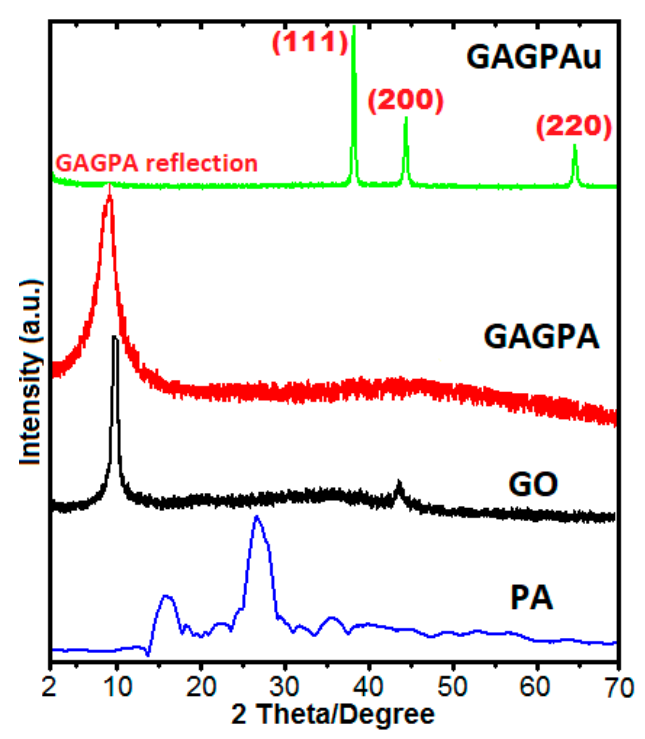

(a)

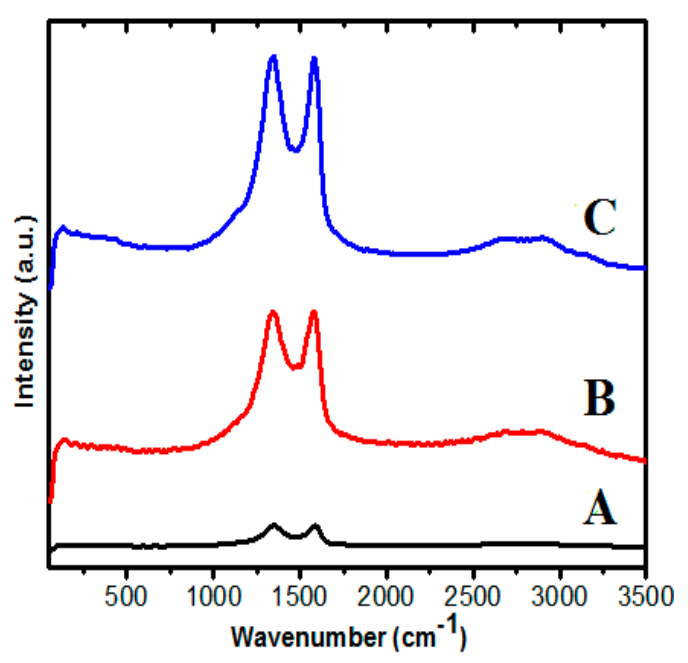

(b)

Figure 2. (a) PXRD diffractograms of the pure protocatechuic acid, GO nanosheets, protocatechuic acid loaded on GO/Gd nanolayers (GAGPA) and gold nanoparticles coated on GAGPA nanocomposite (GAGPAu); (b) Raman spectra of GO nanosheets (A), protocatechuic acid loaded on GO/Gd nanolayers (GAGPA) (B) and gold nanoparticles coated on GAGPA nanocomposite (GAGPAu) (C). 


\subsection{Raman Spectroscopy Studies}

The degree of disorder that is induced by drug loading through hydrogen boding as well as surface coating with AuNPs was assessed through Raman spectroscopy using the Raman shift. The disorder peaks ( $D$ band) and graphitic peaks ( $G$ band) obtained from the pure GO and after successive loadings with the guest materials (GAGPA and GAGPAu) were studied to support other studies conducted on the GOTS and the nanocarrier. It can be seen in Figure $2 b$ that the visible variations in the bands intensities of the samples at different levels of loading. The intensities of the bands appear to be increasing at every stage of modification, starting with GO nanosheets in Figure $2 b(A)$. The intensity of the $D$ and $G$ bands are lower than the intensities of the $D$ and $G$ bands of the GAGPA nanocomposite (Figure $2 b(B)$ ). Consequently, the intensities of the D and G bands of GAGPA are lower than those of the GAGPAu nanocomposite (Figure $2 b(C)$ ). This is presumably due to the surface interactions that occurred between the GO and the PA molecules (mainly hydrogen bonding and $\pi-\pi$ interactions), and subsequently between the GO nanosheets and the positively charged AuNPs (electrostatic interactions) [12].

In addition, the $I_{D} / I_{G}$ intensity ratios appear to be increasing slightly in the order of the surface activities. The relative intensity ratio of $\mathrm{D}$ to $\mathrm{G}$ bands $\left(\mathrm{I}_{\mathrm{D}} / \mathrm{I}_{\mathrm{G}}\right)$ serve to indicate the degree of disorder/functionalization in a graphitic material [28] and are non-proportionate to the $\mathrm{sp}^{2}$-carbon clusters sizes [29]. The $\mathrm{sp}^{2}$-carbon atoms are believed to be the site of the $\pi-\pi$ interactions [12]. Nevertheless, the estimated $\mathrm{I}_{\mathrm{D}} / \mathrm{I}_{\mathrm{G}}$ of the pure GO, GAGPA and GAGPAu nanocomposites are 0.84 , 0.85 and 0.95 , respectively. This slight increase after every stage of modification is also an indication of successive interactions at the various stages of the GO-based nanocomposite synthesis. Similar observations have been previously reported by other researchers who conjugated GO with other therapeutics in drug delivery applications [23].

\subsection{Thermal Studies}

The thermal changes of the GO nanolayers at different levels of modification were monitored by TGA/DTG analysis. The thermal activities were used to support other studies in the confirmation of the GOTS formation at various stages. The thermal decompositions of the pristine GO nanosheets were first studied to confirm the initial formation of the GO nanolayers from graphite source by the improved Hummer's method. Consequently, the thermal studies of the pure PA, the GAGPA and GAGPAu nanocomposites were followed. Figure $3 a-d$ and Table 2 present the thermograms of pure GO, pure PA, GAGPA and GAGPAu nanocomposites. Table 2 also highlights some of the important parameters associated with the thermal activities, which include, decomposition temperature range ( $\left.\mathrm{T}_{\text {range }}\right)$, maximum peak temperature $\left(\mathrm{T}_{\max }\right)$ and change in mass [(decomposition mass) Delta $\mathrm{m}$ ]. The GO thermogram (Figure 3a) did not show much activity, only three decompositions can be observed, starting with decomposition at $71{ }^{\circ} \mathrm{C}(16.4 \%)$ due to loss of water, second and the major decompositions at $197(30.4 \%)$ is due to breakdown of the GO bonds, that is graphene to oxygen functional groups (reduction) and lastly the residue at $255^{\circ} \mathrm{C}(9.7 \%)$ [25].

Table 2. Decomposition temperature range $\left(\mathrm{T}_{\text {range }}\right)$ maximum peak temperature $\left(\mathrm{T}_{\max }\right)$ and change in mass (Delta m).

\begin{tabular}{cccc}
\hline Sample & $\mathbf{T}_{\text {range }}\left({ }^{\circ} \mathrm{C}\right)$ & $\mathbf{T}_{\max }\left({ }^{\circ} \mathrm{C}\right)$ & Delta $\mathbf{~ m}(\%)$ \\
\hline GO (A) & $71-255$ & 197 & 57 \\
Protocatechuic acid (B) & $122-308$ & 262 & 88 \\
GAGPA (C) & $38-888$ & 200 & 68 \\
GAGPAu (D) & $73-747$ & 537 & 58 \\
\hline
\end{tabular}

The protocatechuic acid thermogram in Figure $3 \mathrm{~b}$ equally shows three decompositions, starting with the removal of absorbed water at $122^{\circ} \mathrm{C}(11.1 \%)$ [26], and followed by PA decomposition at $262^{\circ} \mathrm{C}$ 
$(67.4 \%)$ [27]. The residue from PA decomposed at $308^{\circ} \mathrm{C}(9.1 \%)$. The GAGPA thermogram in Figure 3c shows similar decomposition patterns as the drug and the GO. Although it appears more thermally stable than the GO nanosheets, which could be attributed to the conjugation that occurred as a result of hydrogen bonding between the GO functional groups and the drug. The major decomposition of GO appears at $200{ }^{\circ} \mathrm{C}(34.1 \%)$, which is slightly higher than in its pure form $\left(197^{\circ} \mathrm{C}\right)$. In addition, the PA residue decomposed at much higher temperature $\left(888^{\circ} \mathrm{C}, 18.1 \%\right)$ which is likewise higher than in the pristine PA $\left(308^{\circ} \mathrm{C}\right)$. Thus, GAGPA is considerably more stable than the pristine components. This has been observed by other researchers, where the developed composites appeared to be more stable thermally than the individual GO and the therapeutic agents, which confirms the hydrogen bonding between GO and the drug [5].

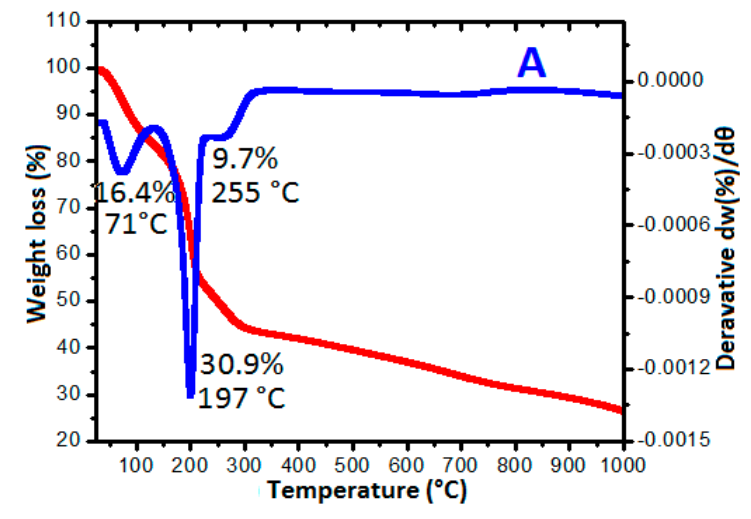

(a)

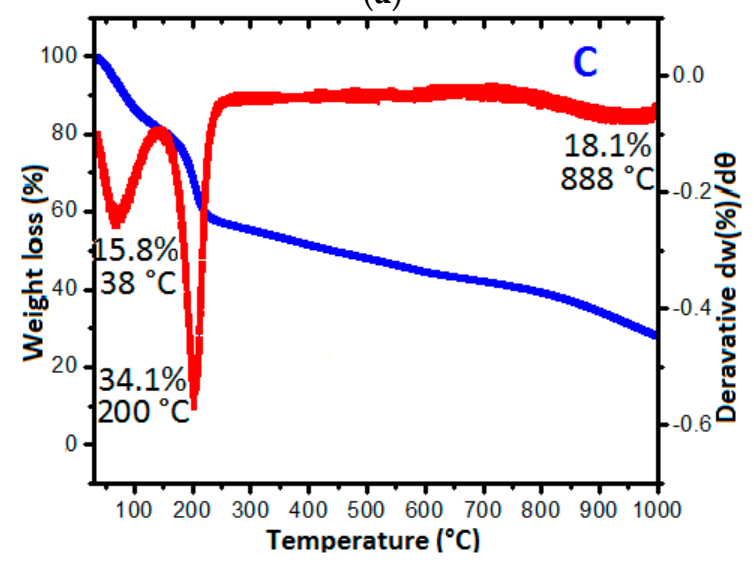

(c)

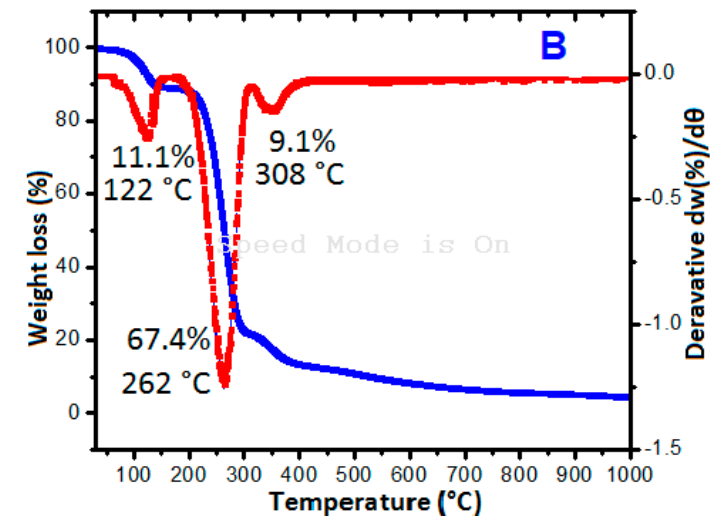

(b)

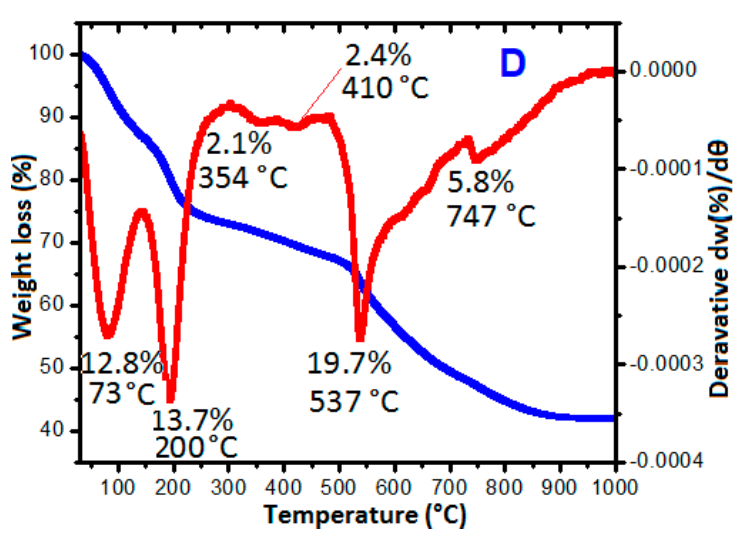

(d)

Figure 3. TGA (Blue) and DTG (Red) thermograms of (a) GO nanosheets; (b) pure protocatechuic acid; (c) protocatechuic acid loaded on GO/Gd nanolayers (GAGPA); (d) gold nanoparticles coated on GAGPA nanocomposite (GAGPAu).

At the last stage of loading (after coating of AuNPs), the thermal events appear to be more than in the previous thermograms. Figure $3 \mathrm{~d}$ is the GAGPAu thermograms, which indicates various decompositions that are linked to the individual loaded guests. The decompositions appear to be fragmented at different temperatures, nevertheless, the major decompositions are at $73{ }^{\circ} \mathrm{C}(12.8 \%)$ $200{ }^{\circ} \mathrm{C}(13.7 \%), 537{ }^{\circ} \mathrm{C}(19.7 \%)$ and $747^{\circ} \mathrm{C}(5.8 \%)$ representing loss of physically-adsorbed water, GO decomposition, PA decomposition and AuNPs decomposition, respectively.

The decompositions have confirmed the successive doping of the guest molecules onto the GO nanocarrier and thus, formation of GO-based TDS [9]. It is also comprehensible that GAGPAu nanocomposite is the most thermally stable amongst its counterparts. 


\subsection{Fourier Transformed Infrared Spectroscopy Analysis}

The chemical interactions between the GO nanosheets and the adsorbed species were further studied with a Fourier transform infrared spectroscopy (FTIR) analysis at various phases' of preparation. The absorptions spectra of the pure GO, pure PA, pure Gd, drug and Gd loaded GO nanocomposite (GAGPA) and the GAGPA nanocomposite coated with AuNPs (GAGPAu) are presented in Figure 4A-E. The GO nanocarrier FTIR spectrum in Figure 4A depicts a broad and intense band of $-\mathrm{OH}$ stretching at $3278 \mathrm{~cm}^{-1}$, which is attributed to the hydroxyl groups that are present in the GO. The broadness of the peak could be due to bonding of the $\mathrm{OH}$ to carbon atoms present in the structure [30]. The stretching vibration of $\mathrm{C}=\mathrm{O}$ bonds is observed at $1721 \mathrm{~cm}^{-1}$, the peak is ascribed to carbonyl and carboxylic acid groups of GO. The band for $\mathrm{C}=\mathrm{C}$ bonds appeared at $1617 \mathrm{~cm}^{-1}$ and are linked to remnant of $\mathrm{sp}^{2}$ or unoxidized carbon structure of graphite [31]. The $\mathrm{COH}$ bonding is observed at $1360 \mathrm{~cm}^{-1}$ [30]. The $\mathrm{C}-\mathrm{O}$ stretching vibrations can be seen at 1162 and $1037 \mathrm{~cm}^{-1}$, which are also attributed to oxidation of GO. In the PA spectrum (Figure 4B), a broad band at $3187 \mathrm{~cm}^{-1}$ is due to $\mathrm{O}-\mathrm{H}$ stretching vibrations [32]. A band at $1666 \mathrm{~cm}^{-1}$ is assigned to $\mathrm{C}=\mathrm{C}$ and the one at $1291 \mathrm{~cm}^{-1}$ is associated with the carboxyl group ( $\mathrm{C}=\mathrm{O}$ stretching) of protocatechuic acid [33]. The carboxylic group $\mathrm{OH}$ bending vibrations appeared between 935 and $551 \mathrm{~cm}^{-1}$. The $\mathrm{Gd}\left(\mathrm{NO}_{3}\right)_{3}$ spectrum is shown in Figure 4C; two bands at 3453 and $3187 \mathrm{~cm}^{-1}$ are linked to $\mathrm{O}-\mathrm{H}$ stretching vibration [30], a band at $1650 \mathrm{~cm}^{-1}$ is associated with $\mathrm{H}_{2} \mathrm{O}$ bending vibration [34]. The two bands at 1444 and $1314 \mathrm{~cm}^{-1}$ are due to the $\mathrm{NO}_{3}$-stretching vibration of the nitrate group [35]. The GAGPA and GAGPAu nanocomposite spectra (Figure 4 D,E, respectively) are similar to the GO spectrum. However, new bands and shift in bands can be observed when compared to the pristine $\mathrm{GO}$, which are resulting from the surface interactions between GO and the loaded compounds. For example, the stretching vibration of $\mathrm{C}=\mathrm{O}$ band at $1721 \mathrm{~cm}^{-1}$ is missing in all the nanohybrids. This is due the hydrogen bonding between carbonyl group of the GO and the PA hydrogen bearing groups.

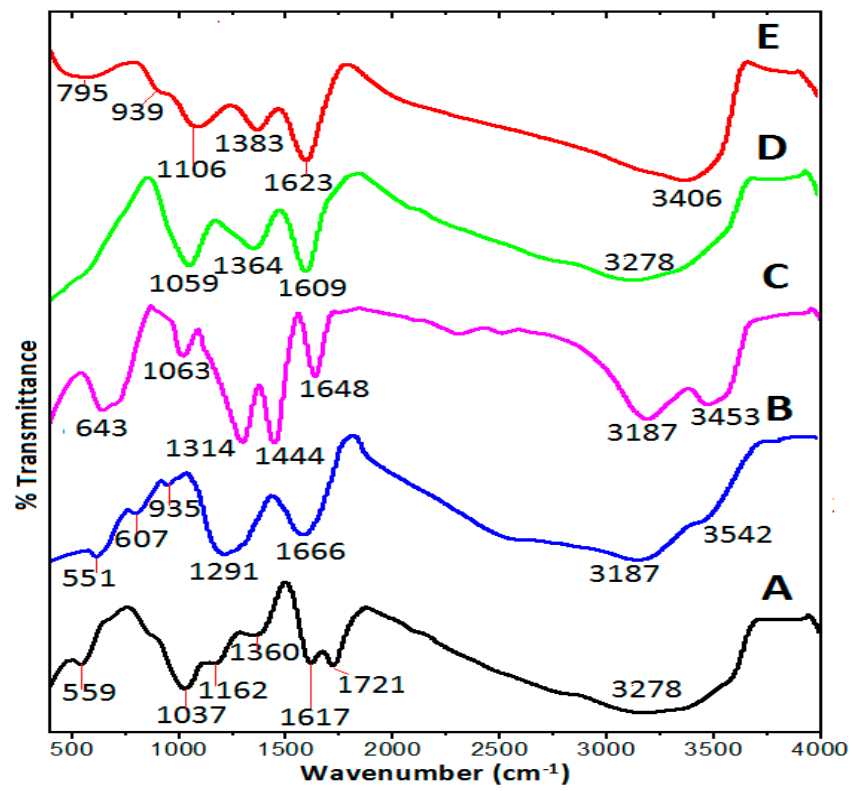

Figure 4. FTIR spectra of GO nanosheets (A); pure protocatechuic acid (B); pure $\mathrm{Gd}\left(\mathrm{NO}_{3}\right)_{3}(\mathrm{C})$ protocatechuic acid loaded on GO/Gd nanolayers (GAGPA) (D); and gold nanoparticles coated on GAGPA nanocomposite (GAGPAu) (E).

Further, the $\mathrm{C}=\mathrm{C}$ absorption band has shifted to 1609 and $1623 \mathrm{~cm}^{-1}$ and has become sharper and stronger in the GAGPA and GAGPAu, respectively. This is presumably due to $\pi-\pi$ interactions, which usually occur at the $\mathrm{sp}^{2}$ carbon [36]. Likewise, the $\mathrm{COH}$ bonding absorptions can be seen to 
have shifted to 1364 and $1383 \mathrm{~cm}^{-1}$ and even stronger in the GAGPA and GAGPAu, respectively. The C-O stretching vibrations have also shifted to 1059 and $1106 \mathrm{~cm}^{-1}$ in the GAGPA and GAGPAu, respectively. These are all indications of surface interactions as observed in the Raman shifts of the pure GO and the nanocomposites.

\subsection{Transmission Electron Microscopy Studies}

The micrographs of the nanocomposites were taken after drug loading and AuNPs coating, GAGPA and GAGPAu, respectively. The purpose of this study is to understand the shapes, sizes and to certain extent the morphology of the developed nanohybrids. Although transmission electron microscopy (TEM) is used in the determination of shapes and sizes, the general morphology can be viewed at low magnifications micrographs. Figure 5a,b are micrographs of the GAGPA and GAGPAu nanocomposites at different magnifications. The GAGPA micrographs show typical multiple layered structure of GO with deposition of the drug on the surface [37]. The deposits of the drug can be seen in the micrographs with $200 \mathrm{~nm}$ magnification, as indicated by the red arrow. This confirms the earlier assertions from XRD, FTIR, Raman spectroscopy and TGA analyses that suggest the successful loading of PA on the GO nanosheets.

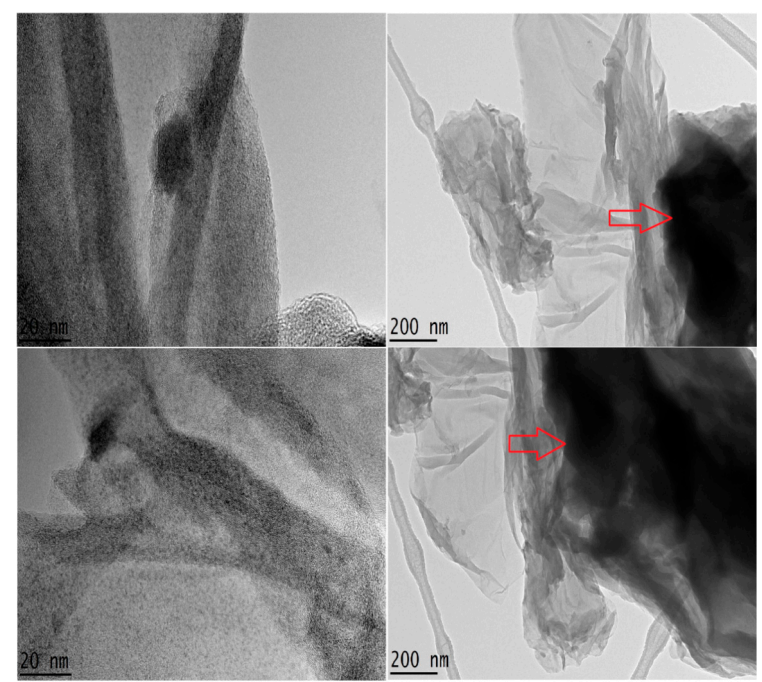

(a)

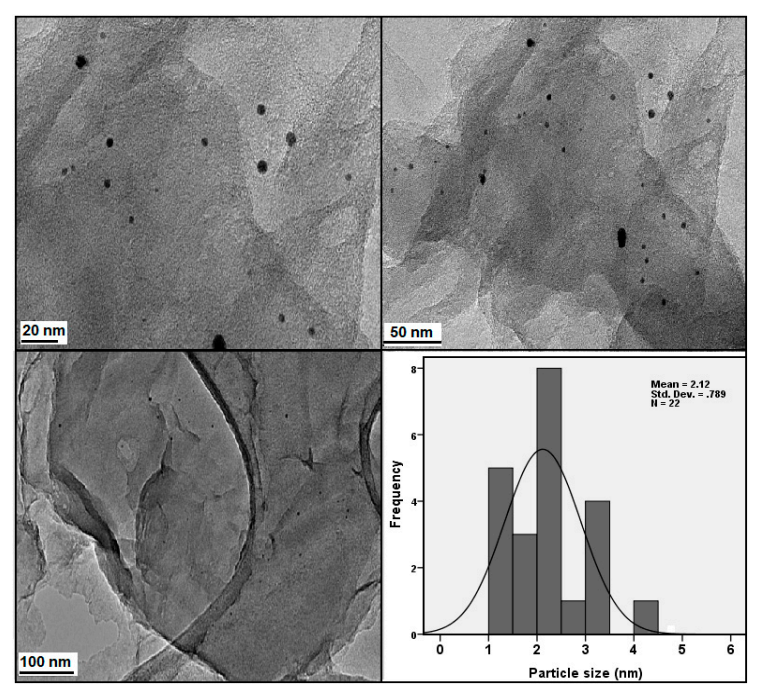

(b)

Figure 5. (a) TEM micrographs of protocatechuic acid loaded on GO/Gd nanocarrier (GAGPA) at high and low magnifications; (b) TEM micrographs of protocatechuic acid loaded on GO/Gd nanocarrier after surface coating with gold nanoparticles (GAGPAu).

On the other hand, the GAGPAu nanocomposite micrographs show predictable outcome, where the positively charged AuNPs can be seen to be adsorbed on the surface of the GO nanosheets. The adsorbed species are believed to be bonded onto the GO surface by electrostatic interactions. Nevertheless, the deposited AuNPs are spherical in shape and predominantly small in size. The mean average size of the AuNPs is around $2 \mathrm{~nm}$, as deduced from the histogram and distribution curve. The results are in agreement with the XRD diffractograms, where pure AuNPs reflections were observed in the GAGPAu nanohybrid. Similar observation has been previously reported by Usman et al. [9], where layered double hydroxide (LDH)-based nanohybrid was surface coated with AuNPs. The micrographs also confirm the earlier assertion of successful formation of a GO-based TDS.

\subsection{Cytotoxicity Studies}

Cytotoxicity studies were conducted to determine the effectiveness of the theranostic nanodelivery system of the anticancer agent. The tests determine the level of toxicity to healthy cells. In doing so, 
two cell lines were used in testing the cytotoxicity of the GO nanocarrier, the final TDS that is after AuNPs doping (GAGPAu) and the anticancer drug, pure PA. Standard fibroblast cell line (3T3) was used to test the safety of the TDS as to healthy cells, whilst human liver hepatocellular carcinoma cell line also known as HepG2, was used for cancer cytotoxicity test.

Figure $6 \mathrm{a}, \mathrm{b}$ show the data expressed in form of histogram obtained from the zones of inhibition of the study in $3 \mathrm{~T} 3$ and HepG2 cell lines, respectively. The samples were dosed in various concentrations; $0.0,1.6,3.1,6.3,12.5,25.0,50.0$ and $100.0 \mu \mathrm{g} / \mathrm{mL}$ for both cell lines. It is evident from the chart that the cells appear to have grown above average in all the concentrations, indicating the TDS, GO and the PA drug are non-toxic towards the 3T3 cells (Figure 6a) even at the highest dose which also suggests that they could be negligibly cytotoxic or nontoxic to healthy human cells.

Contrary to the 3T3 cell lines, the HepG2 shows inhibited growth at $100 \mu \mathrm{g} / \mathrm{mL}$ concentration. The PA and the GAGPAu TDS have shown a high anticancer efficacy at $100 \mu \mathrm{g} / \mathrm{mL}$, where the cancer cells are observed to show growth below average (Figure 6b). This implies that the GOTS could inhibit cancer growth. However, the GO nanocarrier did not indicate any efficacy even at the highest dose, since the cancer cells show almost $100 \%$ growth at $100 \mu \mathrm{g} / \mathrm{mL}$ GO dose. This also suggests the non-susceptibility of the cancer cells towards the GO nanosheets or the non-anticancer properties in the synthesized GO nanosheets. Similar results were reported by He et al. [38], where their GO nanocarrier did not indicate any cytotoxic activity against the cancer cell lines tested.

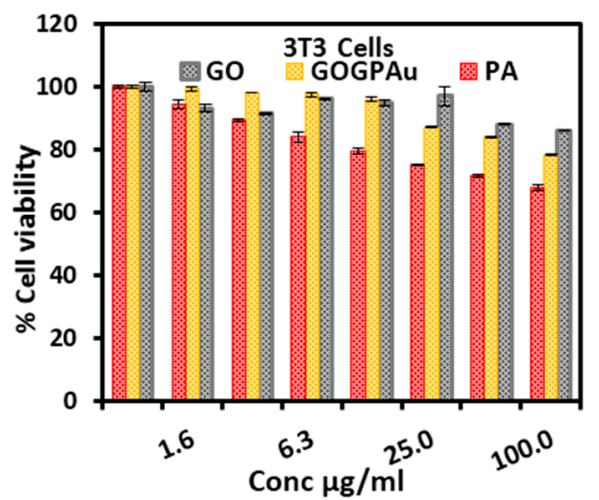

(a)

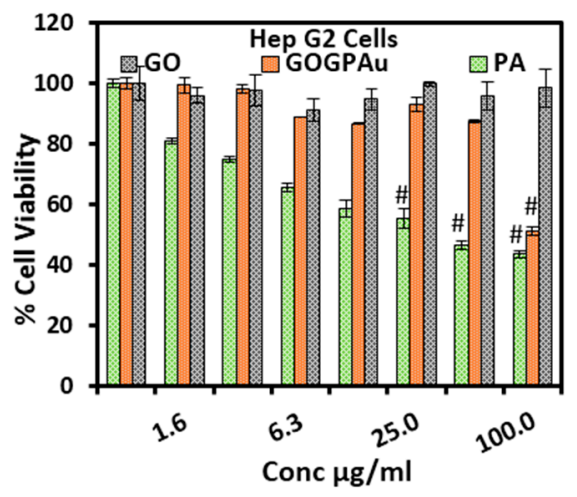

(b)

Figure 6. (a) Cytotoxicity results of pure GO nanosheets, pure protocatechuic acid and protocatechuic acid loaded on GO/Gd nanocarrier after surface coating with gold nanoparticles (GAGPAu) dosed in normal fibroblast cell lines (3T3); (b) cytotoxicity results of pure GO nanosheets, pure protocatechuic acid and protocatechuic acid loaded on GO/Gd nanocarrier after surface coating with gold nanoparticles (GAGPAu) dosed in cancer cell lines (HepG2).

The results have been further tested with t-test statistical analysis for accuracy. No significant difference between all the three tested samples (GAGPAu, PA and GO) was observed in the 3T3 cell lines when compared with the control cells, as revealed by the $p$-value $(p>0.5)$. However, in the HepG2 cells, the last three doses of PA $(6.3,25$ and $100 \mu \mathrm{g} / \mathrm{mL})$ and the last dose of GAGPAu $(100 \mu \mathrm{g} / \mathrm{mL})$ showed significant toxicity as compared to the control cells. The $\mathrm{p}$-value is $p<0.1$.

The high surface area and positively charged surface of the nanocomposites influences the cell penetration either through the low-affinity transmembrane protein pathway or by high-affinity folate receptor. The GO uptake is mostly via clathrin-mediated pathway endocytosis [39]. The results of the cytotoxicity assay have confirmed the nanocomposite has good potential anticancer component in theranostics. 


\subsection{Magnetic Resonance Imaging Studies}

The second theranostic component of the nanocomposite is the diagnostic modality. Magnetic resonance imaging was employed for this purpose. The GOTS was used in the test, which was prepared into various $\mathrm{Gd}^{3+}$ concentrations; 2.0, 0.5 and $0.2 w / v$. In addition, two references were used $\mathrm{Gd}\left(\mathrm{NO}_{3}\right)_{3}(0.5 w / v)$ and water. Figure 7 depicts the T1-weighted image of the aqueous GAGPAu nanocomposite distributed in tubes and the references. The steady rise in brightness of the tubes can be visibly seen, which indicates signal enhancement. This is further confirmed by measuring the intensity of each of the tubes, which expectedly shows the values increasing correspondingly with the $\mathrm{Gd}^{3+}$ concentrations, 2.0 (452.71), 0.5 (338.20) and 0.2 (331.80) $w / v$, Gd $0.5 w / v(235.45)$ and water (228.66). The outcome suggests that the developed nanocomposite has higher contrast properties than the conventional Gd-based contrasts. Gd and AuNPs have individually been used for the enhancement of MRI and CT contrasts, respectively [40-50]. Nevertheless, the agents have been combined for bimodal contrast enhancement of MRI/CT [44,51-53] as well for the sole purpose of MRI signal improvement using different nanocarriers [7,35]. The MRI signals are believed to be improved through improved interaction between $\mathrm{Gd}^{3+}$ ions and GO nanosheets. Moreover, the process is believed to be assisted by the ultrasmall AuNPs at the surface of the GO, which increase the surface area of the nanocomposite, thereby improving water molecular movements within the GO structure [52]. This in turn affects the longitudinal relaxation time (T1 signal) by shortening and reducing the relaxivity, which results in the increase in signal intensity. In addition, the GOTS has an advantage of low toxicity.

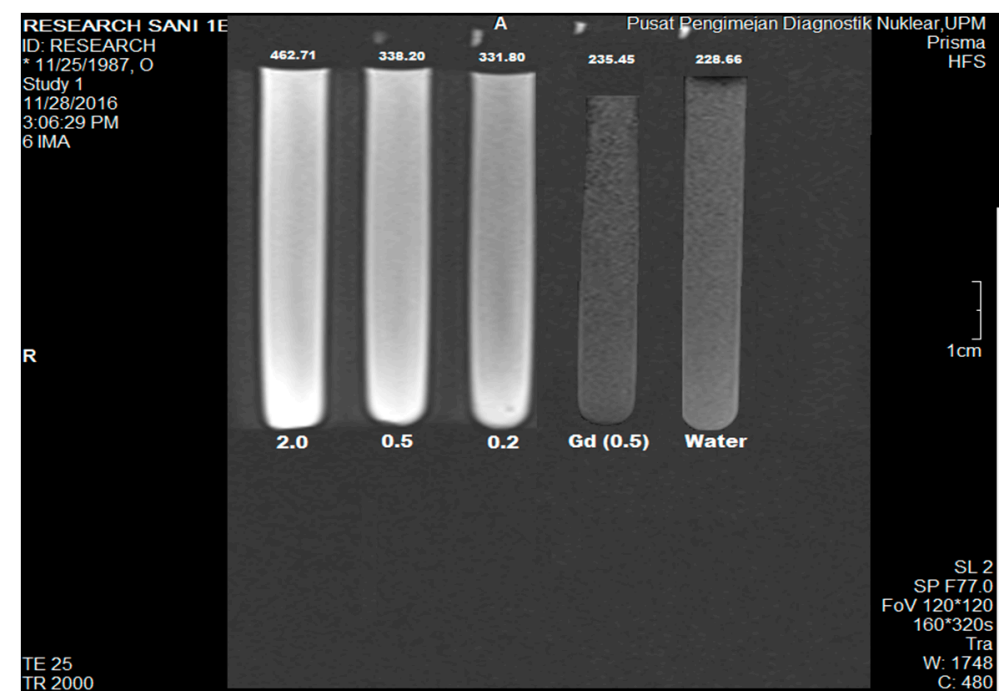

Figure 7. T1-weighted image of protocatechuic acid loaded on GO/Gd nanocarrier after surface coating with gold nanoparticles (GAGPAu) acquired using Prisma 3-Tesla MRI at 2.0, 0.5 and $0.2 w / v$ concentrations of $\mathrm{Gd}^{3+}, 0.5(\mathrm{Gd} w / v)$ and water reference.

\section{Materials and Methods}

\subsection{Materials}

Graphite flakes (100 mesh size), protocatechuic acid (PA) (98\%-170.12 g/mol), phosphatebuffered saline (PBS) potassium permanganate $\left(\mathrm{KMnO}_{4}\right)(99 \%)$, sulphuric acid $\left(\mathrm{H}_{2} \mathrm{SO}_{4}\right)(98 \%)$, hydrogen peroxide $\left(\mathrm{H}_{2} \mathrm{O}_{2}\right)(35 \%)$ and ortho-phosphoric acid $\left(\mathrm{H}_{3} \mathrm{PO}_{4}\right)(85 \%)$ were purchased from Sigma-Aldrich (St. Louis, MO, USA). Hydrochloric acid ( $\mathrm{HCl})(37 \%)$ and diethyl ether (85\%) were supplied by Friedemann Schmidt (Parkwood, WA, USA). Ethyl alcohol (99.7\%) was obtained from Hayman. Tetrachloroauric (III) acid trihydrate (49\% Au-393.83 g/mol) and gadolinium (III) nitrate hexahydrate (99.9\%) were supplied by Acros Organics (Morris Plains, NJ, USA), while human liver 
hepatocellular carcinoma (HepG2) and normal fibroblast (3T3) cell lines were supplied from the American Tissue Culture Collection (ATCC) (Manassas, VA, USA). Deionized water (DI) was used throughout the experiment.

\subsection{Characterization}

The developed nanocomposites were characterized via different techniques. Powder X-ray diffraction (XRD-6000 diffractometer, Shimadzu, Tokyo, Japan), with CuK $\alpha$ radiation $(\lambda=1.5406 \AA$, $40 \mathrm{kV}$ and $30 \mathrm{~mA}$ ) and scan rate of $0.5^{\circ} \theta / \mathrm{min}$. Fourier transformed infrared spectroscopy (FTIR) (Thermo Nicolet model Nicolet 6700) was done with a KBr disc. Raman spectroscopy study was done on a UHTS 300 Raman spectrometer (WITec GmbH, Ulm, Germany) at laser excitation wavelength of $532 \mathrm{~nm}$. High resolution transmission electron microscope (HRTEM), Tecnai TF20 X-Twin (FEI, Hillsboro, OR, USA) was used in studying the GO and the nanocomposites structures as well as the drug loading. UV-visible spectroscopy was used for drug release studies and was conducted on a Lambda 35 ltraviolet-visible spectrophotometer (PerkinElmer, Boston, MA, USA). Thermogravimetric analysis (TGA)/differential thermogravimetric (DTG) was done on a TGA/DSC 1HT model (Mettler Toledo, Shah Alam, Selangor, Malaysia) at heating rate of $10^{\circ} \mathrm{C} / \mathrm{min}$ and nitrogen flow rate of $50 \mathrm{~mL} / \mathrm{min}$.

\subsection{Graphene Oxide (GO) Synthesis}

The improved Hummer's method was adopted in the preparation of the GO nanocarrier. Briefly, concentrated $\mathrm{H}_{2} \mathrm{SO}_{4}(360 \mathrm{~mL})$ and $\mathrm{H}_{3} \mathrm{PO}_{4}(40 \mathrm{~mL})$ were mixed and then added to graphite powder $(3 \mathrm{~g})$ in a $500 \mathrm{~mL}$ beaker. The mixture was stirred for about $5 \mathrm{~min}$ for homogeneity. Under stirring at room temperature, the slow addition of $18 \mathrm{~g} \mathrm{KMnO}_{4}$ was immediately followed. By the end of the $\mathrm{KMnO}_{4}$ addition, the temperature of the mixture rose to about $40{ }^{\circ} \mathrm{C}$. The mixture was further stirred for $12 \mathrm{~h}$ at $50{ }^{\circ} \mathrm{C}$ under dark conditions, then poured into a $400 \mathrm{~mL}$ iced DI. Prior to that, the mixture was allowed to cool down to room temperature. Hydrogen peroxide, $3 \mathrm{~mL}$ was added to the mixture, which melted the ice. The resultant suspension was filtered and washed via a centrifuge with DI (200 mL) first and subsequently with $\mathrm{HCl}$ and ethanol (200 mL each). Finally, the sample was washed with diethyl ether $(200 \mathrm{~mL})$, followed by filtering and drying at $40{ }^{\circ} \mathrm{C}$ in a vacuum oven [18].

\subsection{Synthesis of Graphene Oxide-Gadolinium and Protocatechuic Acid Nanocomposite}

Synthesis of graphene oxide-gadolinium and protocatechuic acid nanocomposite (GAGPA) was prepared by first dissolving the protocatechuic acid $(0.6 \mathrm{~g})$ in aqueous medium $(50 \mathrm{~mL})$ by heating/stirring at $40{ }^{\circ} \mathrm{C}$. Then $0.0008 \mathrm{M}$ gadolinium nitrate was added and stirred for $20 \mathrm{~min}$, after which a clear solution was obtained. GO, $0.2 \mathrm{~g}$ was then added to the solution. The $\mathrm{pH}$ of the mixture was adjusted and maintained at 5.5 using $0.5 \mathrm{M}$ sodium hydroxide solution. The dispersion was allowed to stir for $24 \mathrm{~h}$ at room temperature in a dark condition. The slurry obtained was washed 3 times with DI water. Prior to that, the slurry was centrifuged to collect the precipitate. The sample was dried at $40^{\circ} \mathrm{C}$ in a vacuum over a period of $48 \mathrm{~h}$.

\subsection{Synthesis of Gold Nanoparticles on the GAGPA Nanocomposite Surface}

The GAGPA nanocomposite $(0.15 \mathrm{~g})$ was ultrasonically dispersed in DI $(90 \mathrm{~mL}), \mathrm{HAuCl}_{4}(2 \%$, $6 \mathrm{~mL})$ was added to the dispersion under stirring at room temperature. $\mathrm{NaOH}(0.25 \mathrm{M}, 2 \mathrm{~mL})$ was then added to the mixture and was allowed to stir for $24 \mathrm{~h}$ under nitrogen atmosphere and heating at $60{ }^{\circ} \mathrm{C}$. The mixture was centrifuged and re-dispersed in DI water $(30 \mathrm{~mL}) ; \mathrm{NaBH}_{4}(1 \mathrm{M}, 20 \mathrm{~mL})$ was then introduced and stirred for an hour. The slurry was then centrifuged/washed six times and dried in a vacuum oven at $70{ }^{\circ} \mathrm{C}$ for $24 \mathrm{~h}$. The resulting material is gold nanoparticles on the GAGPA nanocomposite surface. 


\subsection{Drug Loading and Release from GAGPA Nanocomposite}

The release pattern and the amount of the anticancer agent loaded into GAGPA nanocomposite was deduced from the data acquired using a Lambda 35 ultraviolet-visible spectrophotometer. The study was done by first dispersing GAGPA $(25 \mathrm{mg})$ in PBS 7.4 and 4.8 (30 mL of each). The tubes were placed in an oil bath shaker, set at $37{ }^{\circ} \mathrm{C}$. The samples were shaken gently; release media $(3 \mathrm{~mL})$ was withdrawn and replaced with PBS $(3 \mathrm{~mL})$ at predetermined times intervals. The collected media containing the PA that was released from the nanocomposite were analyzed using the UV-Vis spectrophotometer at wavelength maximum $\left(\lambda_{\max }=259 \mathrm{~nm}\right)$.

\subsection{Cytotoxicity Study}

\subsubsection{Cell Culture}

The purchased standard fibroblast (3T3) and carcinoma (HepG2) cell lines were cultured using RPMI 1640 as culture medium (Invitrogen, New Zealand). 10\% fetal bovine serum and 1\% antibiotics (penicillin/streptomycin) were used to supplement the culturing medium. The cells were kept and incubated in a humidified chamber at $37{ }^{\circ} \mathrm{C}$ and $5 \% \mathrm{CO}_{2}$ atmosphere. Culture harvest was done via trypsinization.

\subsubsection{Cytotoxicity Evaluation}

For the toxicity evaluation, 96-wells were plated with grown cells with $1.0 \times 105$ density of cells per well, using $100 \mu \mathrm{L}$ of cell culture medium. A $24 \mathrm{~h}$ attachment period was allowed before the addition of the PA, the nanocarrier (GO) and the GAGPAu nanocomposite at varied concentrations. Incubation period followed (72 h). 3-[4,5-Dimethylthiazol-2-yl]-2,5-diphenyltetrazolium bromide (MTT, $5 \mathrm{mg}$ ) was dissolved in PBS $(2 \mathrm{~mL})$ and distributed into 96-well plates. The cells were incubated at $37^{\circ} \mathrm{C}$, after which formazan product was obtained. DMSO $(100 \mu \mathrm{L})$ was added to the cells and then shaken. Measurement of the optical densities of the cells at $570 \mathrm{~nm}$ was followed. Viabilities of the cells were expressed inform of percentages with the untreated cells as reference. Triplicate experiments and measurements were done all through the experiments for accuracy and mean \pm standard deviations were taken.

\subsection{Magnetic Resonance Imaging Analysis}

Imaging modality test was done on a 3.0 T MRI clinical instrument (3.0 T Siemens Magnetom, Erlangen, Germany). GAGPAu was prepared in three different concentrations (2.0, 0.5 and 0.2), which were based on $\mathrm{Gd}^{3+}$ concentration in the samples. $\mathrm{Gd}\left(\mathrm{NO}_{3}\right)_{3}(0.5 w / v)$ and water were used as references. An MRI phantom was used as holder of the samples, which were placed in the magnetic source area. The samples were imaged with the following conditions: TR/TE: (83/9000) $160 \times 320 \mathrm{~s}$ and field of view (FOV): $120 \times 120$. Analysis of the T1-weighted images was done with Syngovia MRI software (Syngo MR E11, Siemens, Erlangen, Germany, 2013).

\section{Conclusions}

In this work, a theranostic nanodelivery system that consists of both therapeutic and contrast agents were simultaneously loaded onto GO nanosheets for imaging and pharmaceutical applications was successfully prepared. The bimodal theranostic nanodelivery system (GAGPAu) was developed from initial synthesis of $\mathrm{GO}$ nanocarrier, followed by aqueous doping of $\mathrm{Gd}^{3+}$ and protocatechuic acid via hydrogen bonding and $\pi-\pi$ interactions (GAGPA). Subsequently, AuNPs were surface coated through electrostatic interactions (GAGPAu). The drug release study showed above $60 \%$ protocatechuic acid was released in the acidic PBS medium compared to less than $40 \%$ in the alkaline media, suggesting higher drug delivery in the cancer target site. The cytotoxicity studies of the tumor cells further confirmed the drug release study, which showed cancer cell death at $100 \mu \mathrm{g} / \mathrm{mL}$ GAGPAu dose. 
The GOTS appeared nontoxic to normal cells. The GAGPAu contrast enhancement for imaging modalities was tested with Tesla 3.0 MRI equipment. The T1 weighted image of the GOTS dispersions showed increment in contrast of the nanocomposite to be higher than pure $\mathrm{Gd}\left(\mathrm{NO}_{3}\right)_{3}$ and water reference. This preliminary, in vitro result of this research suggests a possible future solution to the highly toxic chemotherapy and diagnosis of cancer diseases. Further studies especially in the in vivo aspect of the GAGPAu are very important for the way forward.

Acknowledgments: The funds for the research were provided by Universiti Putra Malaysia (UPM) and the Ministry of Higher Education of Malaysia (MOHE) under NanoMITe grant Vot No. 5526300.

Author Contributions: The contributions of every author have been highlighted: “Muhammad Sani Usman and Mohd Zobir Hussein conceived and designed the experiments; Muhammad Sani Usman and Aminu Umar Kura performed the experiments; Sharida Fakurazi and Mas Jaffri Masarudin analyzed the data; Mohd Zobir Hussein, Fathinul Fikri Ahmad Saad and Sharida Fakurazi contributed reagents/materials/analysis tools; Muhammad Sani Usman wrote the paper." All authors read and edited the paper before submission.

Conflicts of Interest: The authors declare no conflict of interest.

\section{References}

1. Usman, M.S.; Ibrahim, N.A.; Shameli, K.; Zainuddin, N.; Yunus, W.M.Z.W. Copper nanoparticles mediated by chitosan: synthesis and characterization via chemical methods. Molecules 2012, 17, 14928-14936. [CrossRef] [PubMed]

2. Hancock, Y. The 2010 Nobel Prize in physics-Ground-breaking experiments on graphene. J. Phys. D 2011, 44, 473001. [CrossRef]

3. Novoselov, K.S.; Geim, A.K.; Morozov, S.V.; Jiang, D.; Zhang, Y.; Dubonos, S.V.; Grigorieva, I.V.; Firsov, A.A. Electric field effect in atomically thin carbon films. Science 2004, 306, 666-669. [CrossRef] [PubMed]

4. Goenka, S.; Sant, V.; Sant, S. Graphene-based nanomaterials for drug delivery and tissue engineering. J. Control. Release 2014, 173, 75-88. [CrossRef] [PubMed]

5. Huang, Y.-S.; Lu, Y.-J.; Chen, J.-P. Magnetic graphene oxide as a carrier for targeted delivery of chemotherapy drugs in cancer therapy. J. Magn. Magn. Mater. 2017, 427, 34-40. [CrossRef]

6. Kim, J.; Cote, L.J.; Kim, F.; Yuan, W.; Shull, K.R.; Huang, J. Graphene oxide sheets at interfaces. J. Am. Chem. Soc. 2010, 132, 8180-8186. [CrossRef] [PubMed]

7. Usman, M.S.; Hussein, M.Z.; Fakurazi, S.; Ahmad Saad, F.F. Gadolinium-based layered double hydroxide and graphene oxide nano-carriers for magnetic resonance imaging and drug delivery. Chem. Cent. J. 2017, 11, 47. [CrossRef] [PubMed]

8. Xu, W.; Kattel, K.; Park, J.Y.; Chang, Y.; Kim, T.J.; Lee, G.H. Paramagnetic nanoparticle $\mathrm{T}_{1}$ and $\mathrm{T}_{2}$ MRI contrast agents. Phys. Chem. Chem. Phys. 2012, 14, 12687-12700. [CrossRef] [PubMed]

9. Sani Usman, M.; Hussein, M.Z.; Fakurazi, S.; Masarudin, M.J.; Ahmad Saad, F.F. Gadolinium-Doped Gallic Acid-Zinc/Aluminium-Layered Double Hydroxide/Gold Theranostic Nanoparticles for a Bimodal Magnetic Resonance Imaging and Drug Delivery System. Nanomaterials 2017, 7, 244. [CrossRef] [PubMed]

10. Carr, D.; Brown, J.; Bydder, G.; Steiner, R.; Weinmann, H.; Speck, U.; Hall, A.; Young, I. Gadolinium-DTPA as a contrast agent in MRI: Initial clinical experience in 20 patients. Am. J. Roentgenol. 1984, 143, 215-224. [CrossRef] [PubMed]

11. Nguyen Ngoc, L.; Le Van, V.; Chu Dinh, K.; Sai Cong, D.; Cao Thi, N.; Pham Thi, H.; Nguyen Duy, T.; Luu Manh, Q. Synthesis and optical properties of colloidal gold nanoparticles. J. Phys. Conf. Ser. 2009, 187, 012026.

12. Balcioglu, M.; Rana, M.; Yigit, M.V. Doxorubicin loading on graphene oxide, iron oxide and gold nanoparticle hybrid. J. Mater. Chem. B 2013, 1, 6187-6193. [CrossRef]

13. Sun, X.; Liu, Z.; Welsher, K.; Robinson, J.T.; Goodwin, A.; Zaric, S.; Dai, H. Nano-graphene oxide for cellular imaging and drug delivery. Nano Res. 2008, 3, 203-212. [CrossRef] [PubMed]

14. Yin, M.-C.; Lin, C.-C.; Wu, H.-C.; Tsao, S.-M.; Hsu, C.-K. Apoptotic effects of protocatechuic acid in human breast, lung, liver, cervix, and prostate cancer cells: Potential mechanisms of action. J. Agric. Food Chem. 2009, 57, 6468-6473. [CrossRef] [PubMed]

15. Chao, C.-Y.; Yin, M.-C. Antibacterial effects of roselle calyx extracts and protocatechuic acid in ground beef and apple juice. Foodborne Pathog. Dis. 2009, 6, 201-206. [CrossRef] [PubMed] 
16. Jaijoy, K.; Soonthornchareonnon, N.; Panthong, A.; Sireeratawong, S. Anti-inflammatory and analgesic activities of the water extract from the fruit of Phyllanthus emblica Linn. Int. J. Appl. Res. Nat. Prod. 2010, 3, $28-35$.

17. Marcano, D.C.; Kosynkin, D.V.; Berlin, J.M.; Sinitskii, A.; Sun, Z.; Slesarev, A.; Alemany, L.B.; Lu, W.; Tour, J.M. Improved synthesis of graphene oxide. ACS Nano. 2010, 4, 4806-4814. [CrossRef] [PubMed]

18. Guan, S.; Bao, Y.-M.; Jiang, B.; An, L.-J. Protective effect of protocatechuic acid from Alpinia oxyphylla on hydrogen peroxide-induced oxidative PC12 cell death. Eur. J. Pharmacol. 2006, 538, 73-79. [CrossRef] [PubMed]

19. Sahu, A.; Choi, W.I.; Lee, J.H.; Tae, G. Graphene oxide mediated delivery of methylene blue for combined photodynamic and photothermal therapy. Biomaterials 2013, 34, 6239-6248. [CrossRef] [PubMed]

20. Ehrlich, P. Chemotherapy* A2-HIMMELWEIT, F. In The Collected Papers of Paul Ehrlich; Pergamon: Oxford, UK, 1960; pp. 505-518.

21. Zhang, B.; Yang, X.; Wang, Y.; Zhai, G. Heparin modified graphene oxide for $\mathrm{pH}$-sensitive sustained release of doxorubicin hydrochloride. Mater. Sci. Eng. C 2017, 75, 198-206. [CrossRef] [PubMed]

22. Barahuie, F.; Hussein, M.Z.; Arulselvan, P.; Fakurazi, S.; Zainal, Z. Drug delivery system for an anticancer agent, chlorogenate-Zn/Al-layered double hydroxide nanohybrid synthesised using direct co-precipitation and ion exchange methods. J. Solid State Chem. 2014, 217, 31-41. [CrossRef]

23. Dorniani, D.; Saifullah, B.; Barahuie, F.; Arulselvan, P.; Hussein, M.Z.B.; Fakurazi, S.; Twyman, L.J. Graphene Oxide-Gallic Acid Nanodelivery System for Cancer Therapy. Nanoscale Res. Lett. 2016, 11, 491. [CrossRef] [PubMed]

24. Tang, L.A.; Lee, W.C.; Shi, H.; Wong, E.Y.; Sadovoy, A.; Gorelik, S.; Hobley, J.; Lim, C.T.; Loh, K.P. Highly wrinkled cross-linked graphene oxide membranes for biological and charge-storage applications. Small 2012, 8, 423-431. [CrossRef] [PubMed]

25. Rana, V.K.; Choi, M.C.; Kong, J.Y.; Kim, G.Y.; Kim, M.J.; Kim, S.H.; Mishra, S.; Singh, R.P.; Ha, C.S. Synthesis and drug-delivery behavior of chitosan-functionalized graphene oxide hybrid nanosheets. Macromol. Mater. Eng. 2011, 296, 131-140. [CrossRef]

26. Barahuie, F.; Hussein, M.; Fakurazi, S.; Zainal, Z. Development of Drug Delivery Systems Based on Layered Hydroxides for Nanomedicine. Int. J. Mol. Sci. 2014, 15, 7750-7786. [CrossRef] [PubMed]

27. Barahuie, F.; Dorniani, D.; Saifullah, B.; Gothai, S.; Hussein, M.Z.; Pandurangan, A.K.; Arulselvan, P.; Norhaizan, M.E. sustained release of anticancer agent phytic acid from its chitosan-coated magnetic nanoparticles for drug-delivery system. Int. J. Nanomed. 2017, 12, 2361. [CrossRef] [PubMed]

28. Nasir, S.; Hussein, M.Z.; Yusof, N.A.; Zainal, Z. Oil Palm Waste-Based Precursors as a Renewable and Economical Carbon Sources for the Preparation of Reduced Graphene Oxide from Graphene Oxide. Nanomaterials 2017, 7, 182. [CrossRef] [PubMed]

29. Guo, Y.; Sun, X.; Liu, Y.; Wang, W.; Qiu, H.; Gao, J. One pot preparation of reduced graphene oxide (RGO) or $\mathrm{Au}(\mathrm{Ag})$ nanoparticle-RGO hybrids using chitosan as a reducing and stabilizing agent and their use in methanol electrooxidation. Carbon 2012, 50, 2513-2523. [CrossRef]

30. Verma, S.; Mungse, H.P.; Kumar, N.; Choudhary, S.; Jain, S.L.; Sain, B.; Khatri, O.P. Graphene oxide: an efficient and reusable carbocatalyst for aza-Michael addition of amines to activated alkenes. Chem. Commun. 2011, 47, 12673-12675. [CrossRef] [PubMed]

31. Kuila, T.; Bose, S.; Khanra, P.; Kim, N.H.; Rhee, K.Y.; Lee, J.H. Characterization and properties of in situ emulsion polymerized poly (methyl methacrylate)/graphene nanocomposites. Compos. Part A Appl. Sci. Manuf. 2011, 42, 1856-1861. [CrossRef]

32. Bi, X.; Zhang, H.; Dou, L. Layered double hydroxide-based nano-carriers for drug delivery. Pharmaceutics 2014, 6, 298-332. [CrossRef] [PubMed]

33. Barahuie, F.; Hussein, M.Z.; Gani, S.A.; Fakurazi, S.; Zainal, Z. Synthesis of protocatechuic acid-zinc/ aluminium-layered double hydroxide nanocomposite as an anticancer nanodelivery system. J. Solid State Chem. 2015, 221, 21-31. [CrossRef]

34. Eisenberg, D.; Eisenberg, D.S.; Kauzmann, W. The Structure and Properties of Water; Oxford University Press on Demand: Oxford, UK, 2005.

35. Sun, G.; Zhou, L.; Liu, Y.; Zhao, Z. Biocompatible Gd III-functionalized fluorescent gold nanoclusters for optical and magnetic resonance imaging. New J. Chem. 2013, 37, 1028-1035. [CrossRef]

36. Shen, A.J.; Li, D.L.; Cai, X.J.; Dong, C.Y.; Dong, H.Q.; Wen, H.Y.; Dai, G.H.; Wang, P.J.; Li, Y.Y. Multifunctional nanocomposite based on graphene oxide for in vitro hepatocarcinoma diagnosis and treatment. J. Biomed. Mater. Res. A 2012, 100, 2499-2506. [CrossRef] [PubMed] 
37. Barahuie, F.; Saifullah, B.; Dorniani, D.; Fakurazi, S.; Karthivashan, G.; Hussein, M.Z.; Elfghi, F.M. Graphene oxide as a nanocarrier for controlled release and targeted delivery of an anticancer active agent, chlorogenic acid. Mater. Sci. Eng. C 2017, 74, 177-185. [CrossRef] [PubMed]

38. He, H.; Li, Y.; Jia, X.-R.; Du, J.; Ying, X.; Lu, W.-L.; Lou, J.-N.; Wei, Y. PEGylated Poly (amidoamine) dendrimer-based dual-targeting carrier for treating brain tumors. Biomaterials 2011, 32, 478-487. [CrossRef] [PubMed]

39. Huang, J.; Zong, C.; Shen, H.; Liu, M.; Chen, B.; Ren, B.; Zhang, Z. Mechanism of Cellular Uptake of Graphene Oxide Studied by Surface-Enhanced Raman Spectroscopy. Small 2012, 8, 2577-2584. [CrossRef] [PubMed]

40. Manus, L.M.; Mastarone, D.J.; Waters, E.A.; Zhang, X.Q.; Schultz-Sikma, E.A.; MacRenaris, K.W.; Ho, D.; Meade, T.J. Gd (III)-nanodiamond conjugates for MRI contrast enhancement. Nano Lett. 2009, 10, 484-489. [CrossRef] [PubMed]

41. Pylypchuk, I.V.; Kołodyńska, D.; Kozioł, M.; Gorbyk, P. Gd-DTPA Adsorption on Chitosan/Magnetite Nanocomposites. Nanoscale Res. Lett. 2016, 11, 1-10. [CrossRef] [PubMed]

42. Zhang, H.; Wu, H.; Wang, J.; Yang, Y.; Wu, D.; Zhang, Y.; Zhang, Y.; Zhou, Z.; Yang, S. Graphene oxide-BaGdF 5 nanocomposites for multi-modal imaging and photothermal therapy. Biomaterials 2015, 42, 66-77. [CrossRef] [PubMed]

43. Zhang, L.; Liu, T.; Xiao, Y.; Yu, D.; Zhang, N. Hyaluronic Acid-Chitosan Nanoparticles to Deliver Gd-DTPA for MR Cancer Imaging. Nanomaterials 2015, 5, 1379-1396. [CrossRef] [PubMed]

44. Zhang, L.E.; Zeng, L.; Pan, Y.; Luo, S.; Ren, W.; Gong, A.; Ma, X.; Liang, H.; Lu, G.; Wu, A. Inorganic photosensitizer coupled Gd-based upconversion luminescent nanocomposites for in vivo magnetic resonance imaging and near-infrared-responsive photodynamic therapy in cancers. Biomaterials 2015, 44, 82-90. [CrossRef] [PubMed]

45. Luo, K.; Tian, J.; Liu, G.; Sun, J.; Xia, C.; Tang, H.; Lin, L.; Miao, T.; Zhao, X.; Gao, F. Self-assembly of $\mathrm{SiO}_{2} / \mathrm{Gd}$-DTPA-polyethylenimine nanocomposites as magnetic resonance imaging probes. J. Nanosci. Nanotechnol. 2010, 10, 540-548. [CrossRef] [PubMed]

46. Hedlund, A.; Ahrén, M.; Gustafsson, H.; Abrikossova, N.; Warntjes, M.; Jönsson, J.I.; Uvdal, K.; Engström, M. $\mathrm{Gd}_{2} \mathrm{O}_{3}$ nanoparticles in hematopoietic cells for MRI contrast enhancement. Int. J. Nanomed. 2011, 6, 3233.

47. Fortin, M.A.; Petoral, R.M.; Söderlind, F.; Klasson, A.; Engström, M.; Veres, T.; Käll, P.O.; Uvdal, K. Polyethylene glycol-covered ultra-small $\mathrm{Gd}_{2} \mathrm{O}_{3}$ nanoparticles for positive contrast at $1.5 \mathrm{~T}$ magnetic resonance clinical scanning. Nanotechnology 2007, 18, 395501. [CrossRef]

48. Bellin, M.F. Gadolinium-Based Contrast Agents. In Contrast Media: Safety Issues and ESUR Guidelines; Thomsen, H.S., Webb, J.A.W., Eds.; Springer: Berlin/Heidelberg, Germany, 2009; pp. 199-204.

49. Atabaev, T.; Lee, J.; Shin, Y.; Han, D.-W.; Choo, K.; Jeon, U.; Hwang, J.; Yeom, J.; Kim, H.-K.; Hwang, Y.-H. Eu, Gd-Codoped Yttria Nanoprobes for Optical and T1-Weighted Magnetic Resonance Imaging. Nanomaterials 2017, 7, 35. [CrossRef] [PubMed]

50. Wang, F.; Peng, E.; Zheng, B.; Li, S.F.Y.; Xue, J.M. Synthesis of Water-Dispersible $\mathrm{Gd}_{2} \mathrm{O}_{3} /$ GO Nanocomposites with Enhanced MRI T 1 Relaxivity. J. Phys. Chem. C 2015, 119, 23735-23742. [CrossRef]

51. Le, W.; Cui, S.; Chen, X.; Zhu, H.; Chen, B.; Cui, Z. Facile Synthesis of Gd-Functionalized Gold Nanoclusters as Potential MRI/CT Contrast Agents. Nanomaterials 2016, 6, 65. [CrossRef] [PubMed]

52. Wang, L.; Xing, H.; Zhang, S.; Ren, Q.; Pan, L.; Zhang, K.; Bu, W.; Zheng, X.; Zhou, L.; Peng, W. A Gd-doped $\mathrm{Mg}-\mathrm{Al}-\mathrm{LDH} / \mathrm{Au}$ nanocomposite for CT/MR bimodal imagings and simultaneous drug delivery. Biomaterials 2013, 34, 3390-3401. [CrossRef] [PubMed]

53. Xu, Z.P.; Kurniawan, N.D.; Bartlett, P.F.; Lu, G.Q. Enhancement of relaxivity rates of Gd-DTPA complexes by intercalation into layered double hydroxide nanoparticles. Chem. Eur. J. 2007, 13, 2824-2830. [CrossRef] [PubMed]

Sample Availability: Samples of the compounds are available from the authors. 